\title{
Commentaries
}

\section{Empathy and the Liberal-Conservative Political Divide in the U.S.}

\author{
Stephen G. Morris ${ }^{* a}$ \\ [a] Department of Philosophy, College of Staten Island (CUNY), Staten Island, NY, USA.
}

\begin{abstract}
When future historians look back upon the current political climate in the U.S., it is likely that they will view the severe state of political polarization between liberals and conservatives as being one of its defining characteristics. While some have suggested that a difference in general levels of empathy among liberals and conservatives could be playing a role in shaping their differing political attitudes, psychologist Paul Bloom has forcefully argued against any such difference in his book "Against Empathy". In this commentary I set out to counter Bloom's claim that there is no significant relationship between the capacity to experience empathy and political ideology. To this end, I discuss how a growing collection of empirical research indicates that an individual's propensity to experience empathy correlates with one's general political attitudes (including party affiliation) as well as with which specific policy positions one takes. More specifically, this research suggests that a strong connection exists between empathy and liberal political views. In light of this research, I suggest that empathy can help account for the differences in political attitudes among liberals and conservatives in the U.S. and may even help explain why such attitudes have become increasingly polarized. The analysis provided in this essay aims to further our understanding of how personality traits can be used to predict voter attitudes in the U.S. and beyond.
\end{abstract}

Keywords: empathy, partisanship, polarization, United States, conservatism, liberalism

Journal of Social and Political Psychology, 2020, Vol. 8(1), 08-24, https://doi.org/10.5964/jspp.v8i1.1102

Received: 2018-11-20. Accepted: 2019-09-01. Published (VoR): 2020-02-28.

Handling Editor: Johanna Vollhardt, Clark University, Worcester, MA, USA

${ }^{*}$ Corresponding author at: College of Staten Island, Department of Philosophy, Building 2N, Room 224, 2800 Victory Boulevard, Staten Island, New York 10314, U.S.A. E-mail: stephen.morris@csi.cuny.edu This is an open access article distributed under the terms of the Creative Commons Attribution License
(https://creativecommons.org/licenses/by/4.0), which permits unrestricted use, distribution, and reproduction in any medium, provided
the original work is properly cited.

Empathy is generally understood as the capacity to share in the experiences or emotions that one apprehends in others. Psychologist Paul Bloom's (2016) book Against Empathy is notable for going against many of the prevailing attitudes that people (including both academics and laypersons) have with regard to empathy. First and foremost, Bloom's main focus is to refute the widely accepted view that empathy exerts an overall positive influence on human affairs. Citing various empirical work that exposes some of the negative aspects of empathy, Bloom argues that we would be better off were we to eliminate, or at least minimize, the influence that empathy has over our lives. In the course of building his case against empathy, Bloom turns to the issue of politics and rejects the general consensus view once more, this time with regard to the widely accepted notion that empathy bears a close relationship with liberal political views. 'While Bloom (2016) admits that "there is some association between empathy and [liberal] politics, along the directions that you'd expect," he claims that "the association is not as 
strong as people believe it is" (p. 114). He maintains that "Being against empathy won't tell you what to think about gun control, taxation, health care, and the like; it won't tell you who to vote for, or what your general political philosophy should be like" (Ibid.). In defending this position, he argues that liberals and conservatives are different not in terms of their general levels of empathy, but rather in terms of whom they empathize with. While liberals tend to empathize with certain groups like immigrants, minority victims of police violence, and pregnant women considering whether to have an abortion, conservatives happen to empathize more with individuals like business owners, police officers, and unborn fetuses (2016, p. 122).

According to Bloom, the disconnect between empathy and liberal policies is best illustrated by how liberals and conservatives differ with regard to climate change. Although liberals are in favor of taking significant steps to counter climate change, Bloom claims that the basic conservative stance against doing so is actually more motivated by empathy than the liberal position. His view is that while the conservative view is driven by a tangible concern for U.S. workers who may lose their jobs if we combat climate change by, for instance, reducing our usage of fossil fuels, the liberal position is based instead on a "pale statistical abstraction" involving hypothetical populations in the future (2016, p. 126). In rejecting the notion that empathy can help explain the differences between liberals and conservatives, Bloom also points out that there are many policies that liberals and libertarians-who studies suggest are the least empathetic political group_agree on, such as the legalization of recreational drugs and gay marriage.

In this essay I aim to refute Bloom's arguments denying a strong connection between empathy and liberal political views by citing a growing collection of empirical research conducted on people's political views which suggests that an individual's propensity to experience empathy correlates with one's general political attitudes (including party affiliation) as well as with which specific policy positions one takes. In light of this research, I argue that empathy might help to explain the differences in political attitudes among liberals and conservatives as well as why politics in the U.S. has become increasingly polarized. It is worth noting from the onset that I will not explore whether empathy is a good thing insofar as public policy is concerned, nor will I be discussing the relative merits and shortcomings of liberal and conservative political perspectives. "Furthermore, I will not even address whether political polarization is a problem that ought to be mitigated. In the present essay my aim will be limited to discussing how empirical evidence lends support to the following claims:

1. Empathy is positively correlated to liberalism;

2. This correlation is most likely due to empathy exerting a causal influence on people's political attitudes;

3. The causal impact that empathy appears to have on political attitudes can go some of the way towards explaining the extreme polarization we currently find in the U.S.

I will briefly speak to these claims and how my treatment of them constitutes a novel contribution to the existing literature on empathy and political attitudes. Though a good amount of research has been conducted on the first claim (whether empathy is correlated to liberal political views), this research has frequently generated ambiguous results that have made it difficult to reach any firm conclusions. Part of my aim in this commentary is to point to how a detailed analysis of the relevant empirical studies can explain away the apparent ambiguities and allow us to conclude that a positive correlation does, in fact, hold between empathy and liberal attitudes. Furthermore, though some studies have built compelling cases indicating that liberals in the U.S. have higher general levels of empathy than conservatives (e.g., Hasson, Tamir, Brahms, Cohrs, \& Halperin, 2018), my analysis goes beyond them in pointing to how empathy is correlated to specific liberal policy preferences as well. Since very little research 
has addressed whether a causal relationship between empathy and political views might explain the alleged correlation that holds among them (the second of these claims), my investigation into this subject is another way that the present essay builds on the existing literature. Finally, this commentary offers the first attempt to explain the growing political divide in the U.S. as stemming partly from a growing disparity in general empathy among that country's liberal and conservative voters (the third and final claim). By addressing these three claims, the analysis provided in this commentary aims to clarify the relationship between empathy and political ideology and, in doing so, holds promise for furthering our understanding of how personality traits can be used to predict voter attitudes and behavior in the U.S. and beyond. As a point of clarification, I will not be suggesting that empathy is either the only or the primary predictor of people's political attitudes, nor that it is the only or primary factor behind increasing political polarization in the U.S. My intention is only to point to research indicating that differing empathy levels seem to provide some explanation for people's political attitudes and may serve as one of the factors contributing to the growing political divide in the U.S.

\section{Liberalism Versus Conservativism}

When future historians look back upon the current political climate in the U.S., it is likely that they will view the severe state of political polarization between liberals and conservatives (who generally align themselves with the Democratic and Republican parties respectively) as being one of its defining characteristics. Acknowledging this polarization of political attitudes, a report by the Pew Research Center (2014) stated that "Republicans and Democrats are more divided along ideological lines - and partisan antipathy is deeper and more extensive - than at any point in the last two decades". An analysis conducted by political scientists Christopher Hare and Keith Poole goes even further, concluding that "Polarization of the Democratic and Republican Parties is higher than at any time since the end of the Civil War" $(2014$, p. 411). It is likely that such ideological divisions have only deepened as of 2020. While numerous explanations have been offered to account for this growing divide in U.S. politics—which include an increasingly partisan mass media (Levendusky, 2013), an upsurge of money into politics (La Raja \& Schaffner, 2015), gerrymandering (Carson, Crespin, Finocchiaro, \& Rohde, 2007; Theriault, 2008), unprecedented inequality (Voorheis, McCarty, \& Shor, 2015), differences in education (Tuschman, 2013), and even the increasing tendency of U.S. citizens to marry politically like-minded individuals (lyengar, Konitzer, \& Tedin, 2018)—-these explanations have overlooked a deeper psychological element, namely empathy, that may be playing a significant role in driving the political rift between liberals and conservatives.

Before delving into how empathy relates to the ideological differences between liberals and conservatives in the U.S., I will briefly discuss the distinction between liberalism and conservatism as well as the basic nature of empathy. In the literature comparing liberalism versus conservatism, an emphasis is often placed on understanding how particular personality variables can predict political preferences. Surveying the contemporary literature on the general personality traits of liberals (i.e., progressives or left-wingers) and conservatives (i.e., right-wingers) reveals a general consensus that liberals tend to be more open to social change, less religious, more egalitarian, less authoritarian, less punitive, more tolerant of out-groups, less concerned with in-group unity, and look less favorably upon hierarchical social structures than conservatives (Alford, Funk, \& Hibbing, 2005; Feldman \& Johnston, 2014; Jost, Federico, \& Napier, 2009; Schwartz, 1992). Furthermore, research indicates that these differences in personality variables can help account for the consistent divergence we observe among liberals and conservatives with respect to policy preference. In terms of economic policies, the more egalitarian and less 
hierarchical bent of liberals tends to make them look much more favorably upon policies aimed at eliminating wealth inequality (e.g., progressive taxation) and providing for the poor (e.g., welfare programs), as well as those seeking to provide all citizens with free access to healthcare and higher education. Another common difference between liberals and conservatives is that while the latter generally desire to uphold traditional social arrangements - which is exhibited by conservatives' less positive attitudes towards the legalization of gay marriage and recreational drug use - the former are generally in favor of promoting social change, especially where they view such changes as being necessary for promoting the welfare of groups they believe have been subject to discrimination. Hence, liberals are much more favorable in their attitudes towards affirmative action, immigration, and laws aimed at protecting the LGBTQ community.iii Finally, conservatives tend to place more of an emphasis on protecting citizens from aggression by either fellow citizens or foreigners. This helps explain why conservatives tend to have more favorable attitudes towards military spending and harsher punishment of convicted criminals than liberals. While this discussion of the distinction between liberals and conservatives is admittedly cursory, this snapshot of these two political groups in the U.S. suffices for the purposes of this essay.

\section{The Components of Empathy}

In a series of articles $(2014,2015)$, neuroscientist Jean Decety and psychologist Jason M. Cowell describe empathy as being constituted by three distinct, yet related, components:

1. Affective Sharing which reflects the natural capacity to become affectively aroused by others' emotions. It occurs when you feel what another is feeling (or what you imagine another is feeling).

2. Empathic Concern, which corresponds to the motivation of caring for another's welfare.

3. Perspective Taking, which is the ability to consciously put oneself into the mind of another individual and imagine what that person is thinking or feeling $(2015$, p. 4).

While Decety and Cowell identify both affective sharing and empathic concern as being ancient adaptations that we find in non-human animals, they view perspective taking as being a much more recent evolutionary development that is found only in human beings and perhaps a few of the more developed ape species. And though Decety and Cowell assert that "the biological mechanisms underpinning empathic concern are different from those involved from affective sharing," they believe that these components evolved together and played a pivotal role in both parental care and in-group cooperation, both of which have been important for our species' survival (see 2015, pp. 6-7). The close relationship between these two components probably accounts for Decety and Cowell's tendency to use empathy as a label that includes both affective sharing and empathic concern (see for example, 2015, p. 10).

Decety and Cowell's understanding of empathy corresponds with other conceptions of it in the psychological literature. To illustrate, consider the description of empathy given by Weisz and Zaki (2018) in a recent paper: "empathy is a multicomponent phenomenon comprised of related but distinct sub-processes. These sub-processes include experience sharing (or vicariously feeling others' emotions) [i.e., affective sharing], mentalizing (explicitly considering others' thoughts and internal states) [i.e., perspective taking], and empathic concern (positive feelings of compassion and care for others' welfare)" (p. 67). Preckel, Kanske, and Singer (2018) express a similar description of empathy, stating that "empathy enables the sharing of another's emotion [i.e., affective sharing] and may result 
in...compassion, a feeling of warmth and concern for others [i.e., empathic concern]" and "provides cognitive understanding of someone else's thoughts or intentions [i.e., perspective taking]" (p. 1). Other descriptions of empathy in the psychological literature that reflect Decety and Cowell's conception of it are plentiful.

To begin with affective sharing, it is basically the default definition of "empathy" that we find throughout the literature. In a widely-cited review paper, for instance, social psychologists Goetz, Keltner, and Simon-Thomas (2010) define empathy as "the vicarious experience of another's emotions" (p. 351). Empathic concern is commonly identified as being a key component of empathy and has been discussed extensively by the eminent social psychologist C.D. Batson (e.g., Batson, 2009). Finally, numerous psychologists have recognized perspective-taking (sometimes called "cognitive empathy") as being the cognitive facet of empathy (Bloom, 2016; Deutsch \& Madle, 1975; Dillard \& Hunter, 1989). It is also worth mentioning that Mark Davis's (1980) influential Interpersonal Reactivity Index that is used to measure empathy contained items that measured affective sharing, empathic concern, and perspective taking.

\section{The Correlation Between Empathy and Liberalism}

Before I address the empirical case that can be made for the connection between empathy and liberal political attitudes, it is worth noting that the view that such a connection exists has strong intuitive appeal. This view, for example, comports with the disparaging depiction of liberals as "bleeding hearts" whose policy preferences are often driven by a concern for the welfare of disadvantaged groups within a society. Speaking to this common conception, philosopher Jesse Prinz (2011) says: "Conservatives tend to be less empathetic, and they think the needy should pull themselves together and solve some of their own problems rather than looking for handouts" (p. 223). Despite this common attitude, however, research conducted on the relationship between empathy and ideology has often been ambivalent about whether empathy correlates with liberal attitudes in a straightforward fashion. ${ }^{\text {iv }}$ This ambivalence is probably one of the factors that led Bloom to forcefully argue against the idea of a close relationship between empathy and liberal political views in his 2016 book Against Empathy. In what follows I set out to counter those like Bloom, who maintain that the available empirical data fails to provide a robust case for believing that the capacity to feel empathy for others is positively tied to liberal political views. As I intend to show, the bulk of the empirical work on empathy and political attitudes offers strong reasons for rejecting Bloom's position. Before proceeding to discuss the empirical studies relevant to this matter, however, some discussion of the methods used in these studies is in order, particularly regarding how empathy was measured.

In the studies exploring the connection between empathy and political attitudes that I will discuss, the methods that researchers used for measuring empathy typically involve asking subjects to rate themselves according to the components of empathy (affective sharing, empathic concern, and perspective taking) mentioned earlier. Thus, for instance, the Interpersonal Reactivity Index (Davis, 1980)—hereafter the IRI—which was used in several of these studies includes questions such as, "I sometimes find it difficult to see things from the 'other guy's' point of view" (perspective taking), "Sometimes I don't feel very sorry for other people when they are having problems" (empathic concern), and "I really get involved with the feelings of the characters in a novel" (affective sharing). The Empathy Assessment Index (hereafter EAI) developed by Lietz et al. (2011) used many of the types of questions found in the IRI-e.g., "When I see someone receive a gift that makes them happy, I feel happy myself" (affective sharing)—to measure participants' general empathy levels. Other measures of empathy that I cite below-e.g., the Empathy Quotient (EQ) developed by Baron-Cohen and Wheelwright (2004) and the Portrait Values Questionnaire-Revised (PVQ-R) developed by Schwartz et al. (2001)_are similar to the foregoing studies in that 
they either often or exclusively ask questions aimed at measuring the subject's general empathy levels. In addition to these kinds of tests involving questionnaires, one of the studies I discuss—-that of Loewen et al. (2019)—used a measure of empathy called the "Reading the mind in the eyes test" (Baron-Cohen, Wheelwright, \& Jolliffe, 1997), which involves testing the degree to which subjects can accurately determine the emotional state of an individual by just viewing that individual's eyes.

In terms of the reliability of these different measures, recent work in neuroscience suggests that at least some of them are successful in measuring key components of empathy (Stueber, 2013). For instance, a study by Gazzola, Aziz-Zadeh, and Keysers (2006) identified a correlation between regions of the brain associated with perspective taking and higher scores on the IRI. Another study by Lamm, Batson, and Decety (2007) found that higher scores on the EQ correlated with brain regions involved with both perspective taking and empathic concern. What is notable is that while the studies discussed below invoke different measures to test for empathy, the vast majority of them-all but one in fact, which I discuss below-converge upon the same conclusion; namely, that people measuring higher in general empathy tend to harbor liberal political views.

Despite Bloom's denial of a close connection between empathy and political partisanship, the bulk of the empirical evidence suggests that empathy is a strong predictor of political outlook and affiliation. On the one hand, several studies (Hasson et al., 2018; Loewen et al., 2019; Wagaman \& Segal, 2014) have identified empathy as a powerful and independent variable that tracks general ideological differences between the two sides. On the other hand, numerous studies (Jylhä \& Akrami, 2015; Loewen et al., 2019; Newman, Hartman, Lown, \& Feldman, 2015; Unnever et al., 2005; Westman \& Lewandowski, 1991) indicate that differences in empathy correspond to the disagreements that liberals and conservatives have on specific issues such as war, affirmative action, and climate change. In terms of general political attitudes, an overwhelming majority of the empirical research suggests that a person's tendency to experience empathy bears a positive correlation with their propensity to harbor liberal attitudes. One indication that conservatives are generally less empathetic than liberals comes from a Pew Research study in which conservatives placed less emphasis on empathy in terms of its importance of teaching to children. The percentage of subjects who considered teaching "empathy for others" to children as being "most important" relative to other traits such as "creativity" and "obedience" corresponded directly to one's partisan leanings, reaching its highest point among those identifying as "consistently liberal" (86\%) and its lowest point among those identifying as "consistently conservative" (55\%) (Green, 2014). Attitudes about teaching empathy to children are relevant to determining a person's capacity to feel empathy since most scholars believe that the teaching of empathy at a very early age is crucial for its development (see for example Hoffman, 2001). Waytz, lyer, Young, and Graham (2016, p. 63) point to another way that the empirical evidence suggests a connection between empathy and political preferences by highlighting how self-reported empathy and SDO-i.e., social dominance orientation which is a trait that reflects endorsement of social hierarchy and which is associated with conservatism-are negatively associated with each other.

Additional research points to a more direct connection between empathy and political orientation. In one study Waytz et al. (2016, p. 62) observed that scores conducted on a general empathy measure (in this case items taken from the IRI) were positively correlated with policies that are typically supported by liberals. ${ }^{v}$ In 2014 Wagaman and Segal (2014) conducted a study that explored the relationship between empathy and attitudes about government intervention (a subject looked more favorably upon by liberals than conservatives) among a population of U.S. college students. Controlling for other factors such as gender, race and economic status, the researchers found that higher levels of empathy were associated with more positive attitudes towards government intervention with 
regard to social welfare (Wagaman \& Segal, 2014, p. 102). ${ }^{\text {vi }}$ Additional evidence for a connection between empathy and political ideology was discovered by Hasson et al. (2018), whose studies indicate that liberals were more motivated to feel empathy and felt more empathy $(M=4.89, S D=1.61)$ than conservatives $(M=4.33, S D=1.8)$. . $^{\text {ii }}$ In another study conducted on empathy and political views, Loewen, Cochrane, and Arsenault (2019) generated results indicating a strong parallel between differences in general empathy and differences in political attitudes. Using both self-reports of empathy (via the EQ) and the "Reading the mind in the eyes" test on a representative sample of Canadian citizens, they found that "partisanship varies systematically with the individual differences in empathy" (Loewen et al., 2019, p. 2) and that "the probability of identifying with the Conservative party declines as empathy increases" (p. 11). ${ }^{\text {viii }}$ Moreover, Loewen et al. (2019, p. 11) found that empathy "exercises an independent and substantively impressive effect," both in regards to party preference (i.e., general political outlook) as well as the stance one takes on specific issues. In fact, their studies indicate that the connection between empathy and liberal politics is so strong that more empathetic individuals were willing to support liberal policies even when doing so came at a significant personal cost, such as higher taxes or longer medical wait times.

Loewen et al.'s finding that a person's empathy level is correlated with liberal policy preferences is bolstered by similar findings from multiple studies which I will discuss shortly. So what are we to make of Bloom's claim to the contrary? Recall that he focuses on the issue of climate change to demonstrate that empathy does not necessarily (or even most frequently) align with liberal policy preferences. Bloom's assumption that higher empathy levels would lead one to take the conservative stance against implementing policies to combat climate change is directly countered by the research of Jylhä and Akrami (2015), who found that subjects registering low in empathy were more likely to be climate change deniers. ${ }^{\text {ix }}$. It is worth noting here that Loewen and his colleagues (2019) also obtained evidence that higher levels of empathy are associated with a greater desire to combat climate change, as well as with other liberal causes such as providing free education and free health care.

Other research shows a similar connection between empathy and specific liberal policy aims. Wagaman and Segal (2014) ran a study in which subjects measuring higher in empathy were more supportive towards government programs supporting affirmative action and protecting the rights of minorities in general. ${ }^{\mathrm{x}}$ In a study aimed at determining the relationship between empathy and attitudes towards war, Westman and Lewandowski (1991) found that those registering higher in empathy-more specifically, those whose empathy extends to humanity generally as opposed to one's immediate family, friends, etc. (which, as I discuss below, is the kind of empathy that Waytz et al. [2016] found to be strongly associated with liberals)—were less likely to support the first U.S. war in Iraq. Unnever, Cullen, and Fisher (2005) found that those higher in general empathy tend to take the liberal position against capital punishment. ${ }^{x i}$ Finally, Newman, Hartman, Lown, and Feldman (2015) found that empathy was negatively correlated to the kinds of restrictive immigration policies favored by conservatives. ${ }^{\text {xii }}$ All of this serves as a powerful rejoinder to Bloom's assertion that there is no solid connection between empathy and liberal policy preferences. It is worth noting that there is some evidence suggesting that a connection between empathy and liberal political attitudes may extend beyond U.S. borders. To see why, consider how the data that Loewen et al. (2019) collected came from Canadian citizens and the data used by Hasson et al. (2018) came from German, Israeli, and U.S. citizens. Future research on empathy and its connection to political views could help shed the light on the extent to which the apparent correlation between empathy and liberal attitudes in the U.S. generalizes to other countries and socio-political contexts. 


\section{An Objection Considered}

While the vast majority of empirical evidence suggests that liberals have higher general levels of empathy than conservatives, not all studies conducted on the relationship between empathy and political attitudes lend clear support for this conclusion. In their study on the differences in empathy among liberals and conservatives, Waytz et al. (2016, p. 70) conclude that while liberals and conservatives are different in terms of who or what the targets of their empathy are, they do not diverge in terms of their absolute levels of empathy. Drawing from experiments they conducted, they conclude that while conservatives' empathy is geared towards smaller social groups (family, friends, members of the same country), the empathy of liberals extends to larger populations including members of other countries, religions, and even to non-human animals. ${ }^{\text {xii }}$ Such research aligns with Bloom's (2016) claim that liberals and conservatives do not differ with regard to general levels of empathy; rather, they differ only in terms of which groups liberals and conservatives empathize with. At this point a question presents itself: How can it be that the studies discussed by Waytz et al. (2016) generated results indicating that liberals and conservatives do not exhibit differing levels of general empathy when the vast majority of prior studies indicate that liberals and conservatives do differ in this respect? For a possible explanation, it may be helpful to look at research that was conducted to test another long-standing claim regarding differences between liberals and conservatives; namely, that conservatives are generally more intolerant than liberals.

Brandt, Reyna, Chambers, Crawford, and Wetherell (2014) set out to test the consensus view that conservatives are generally more intolerant than liberals. ${ }^{\text {xiv }}$ What they found was that popular opinion notwithstanding, liberals and conservatives demonstrated similar levels of intolerance towards groups that were considered to be either ideologically dissimilar to themselves or threatening. Thus, while conservatives demonstrated intolerance towards their traditional ideological opponents-e.g., pro-choice advocates, welfare recipients—liberals were equally intolerant towards their traditional ideological opponents—e.g., pro-life advocates, Christian Fundamentalists. So why did so many prior studies get the relationship between political ideology and intolerance wrong? The answer given by Brandt et al. (2014) is that prior studies were biased by the kinds of prompts that were given to subjects. It turns out that most of the prompts used in these studies involved questioning subjects about their tolerance towards groups that tend to hold liberal political views (e.g., Black Americans). According to Brandt et al. (2014) it was the perceived ideological differences with the target group, rather than, say, a basic dislike of Black Americans, that fostered conservatives' intolerance towards this group. In support of their view, they point out that when conservatives were presented with information stating that a black individual in a particular case possessed a conservative ideology, the intolerance disappeared. ${ }^{\mathrm{xV}}$

With Brandt et al.'s (2014) insights about how investigations into alleged differences between liberals and conservatives can be skewed due to biased prompts, we can now return to the issue of empathy and ask whether the studies indicating that liberals are more empathetic than conservatives have also been hampered by similarly biased prompts. If it should turn out that these studies primarily employed prompts in which subjects were asked to rate their empathy towards groups who tend to harbor liberal political views, then we should expect liberals to give higher empathy responses than conservatives. Along the lines of what Brandt and his associates argue, such results would not justify the generalization that liberals are more empathetic than conservatives. In order to justify this more general conclusion, the bias in the study would have to be removed by, for instance, prompting subjects to state their felt empathy towards different groups exhibiting a wide array of political views, some more liberal, some more conservative, and some perhaps politically neutral. Were it to turn out that either liberals or conservatives 
tended to exhibit more overall empathy than the other with regard to all of these groups taken together, this could serve as a compelling reason to consider the one political group more empathetic than the other.

So is there reason to believe that the studies indicating that liberals are more empathetic than conservatives were biased in a way that parallels the studies investigating ideologically-based intolerance that Brandt et al. (2014) took to task? A good reason for denying that these empathy studies were biased in this way stems from the fact that the primary methodology they used to determine subjects' empathy levels involved having subjects rate themselves according to general statements related to empathy as opposed to having them state how empathetic they feel towards specific types of targets who tend to be associated with a particular political ideology. Consider how in the studies run by Brandt et al. (2014), subjects were asked to state their beliefs and attitudes toward identifiable groups (e.g., liberals, business people, feminists, Republicans, etc.) by rating their level of agreement to statements such as, "Republicans should not be allowed to make a speech in this city." "Ni Now contrast this to representative examples of the kinds of prompts employed in the studies used to measure general empathy that I have discussed: "I really enjoy caring for other people" (EQ); "I try to look at everybody's side of a disagreement before I make a decision" (IRI); "When I see a stranger crying, I feel like crying" (EAI); "It is important to him/her that everyone be treated justly, even people [he/she] doesn't know. (PVQ-R). ${ }^{\text {xvii }}$ It should be apparent that the foregoing examples of statements used to gauge subjects' empathy do not involve asking subjects to state their feelings about specific groups that they may or may not share political attitudes with. This being the case, it would seem that the kinds of biases that Brandt and his associates (2014) revealed with regard to studies conducted on ideological differences and intolerance are not likely to be impacting the aforementioned studies of how empathy is related to political ideology. Consequently, there does not appear to be a compelling reason for thinking that these studies on empathy were biased in a way that should make us question their results. But if it is true that there are no obvious reasons to doubt the veracity of studies indicating that liberals have higher general levels of empathy than conservatives, how can we reconcile them with the results of Waytz et al.'s (2016) studies suggesting that liberals and conservatives differ only with regard to their targets of empathy as opposed to their general empathy levels? Studies conducted on empathy by Hasson et al. (2018) provide insight into how to go about reconciling these opposing conclusions.

Hasson et al. (2018) were spurred on by the concern (similar to that of Brandt et al., 2014) that prior studies on the connection between empathy and political ideologies may have been biased insofar as they asked subjects about their empathy towards targets that may be considered to be members of an out-group from a particular ideological perspective. To address this worry, they conducted their own studies involving specific targets that both liberals and conservatives would consider to be either members of an in-group, an out-group, or a neutral group. They did this by identifying subjects as being either more liberal or more conservative and then asking subjects in each of these groups to state the empathy felt towards liberal, conservative, or neutral targets. To help ensure that their results are generalizable, they conducted studies in the U.S., Germany, and Israel. Employing the PVQ-R to measure empathy, Hasson et al. (2018) tested participants' motivation to feel empathy, the amount of empathy they experienced, and their tendency to help others. What they found was that regardless of which target group (political in-group, political out-group, or neutral/non-political group) participants were asked to consider, liberals on average were more motivated to feel empathy and actually experienced more empathy than conservatives. That is, compared to conservatives, liberals tended to express more empathy towards in-group members $(M=5.33$ vs 4.73$)$, out-group members $(M=4.48$ vs. 3.7$)$, and politically neutral parties $(M=5.06$ vs. 4.55). Importantly, these effects were replicated in all three countries in which the studies were conducted. ${ }^{\text {xviii }}$ 
In light of these results, Hasson et al. (2018) consider their research to have both expanded and improved upon the findings of Waytz et al. (2016). Like the latter research group, Hasson et al. (2018) found that both liberals and conservatives were more empathetic to members of the political in-group than to members of the political out-group. In contrast to Waytz and his associates, however, Hasson et al. (2018) found "a more general ideological difference in levels of empathy" such that that liberals were more empathetic regardless of the target group involved (p. 1456). ${ }^{\text {ix }}$ The results of Hasson et al. (2018) offer a compelling reason for rejecting Waytz et al.'s (2016) claim that liberals and conservatives do not differ with regards to general levels of empathy. They also mesh nicely with the other studies on political attitudes and empathy that did not involve the use of specific targets (see above), and which found liberals to be generally higher in empathy than conservatives. In the end, the worry that studies suggesting that liberals admit of more empathy than conservatives are biased seems unfounded.

\section{Exploring the Causal Relationship Between Empathy and Political Ideology}

In the preceding two sections I have argued that numerous studies lend strong support for a positive correlation between empathy and liberal political attitudes, including specific liberal policy preferences. That such a correlation exists, however, does not imply that empathy (or a lack thereof) is playing a causal role in producing people's political perspectives. Assuming that there is some causal connection between empathy and political attitudes, the question of what form this connection takes remains unanswered. When it comes to the nature of the assumed causal relationship between high levels of empathy and liberal political views, three possibilities present themselves:

1. A person's empathy level plays some role in determining one's political preferences;

2. A person's political preferences play some role in determining one's empathy level;

3. There is some third factor that simultaneously impacts empathy levels and political preferences in consistent patterns among different individuals.

In this section I explore the connection between empathy and political beliefs in more detail in order to better understand the causal processes at work.

Of the preceding explanations for the correlation between empathy and political affiliation, the suggestion that empathy (or lack thereof) plays an important causal role in determining a person's political preferences is the most plausible. As I alluded to earlier, this explanation has considerable intuitive appeal. Echoing this sentiment, Sidanius et al. (2013, p. 318) have remarked that finding out that personality variables like empathy can affect sociopolitical beliefs and behaviors would be "no surprise" and the notion that they can has long been theorized by political psychologists. ${ }^{x x}$ This explanation is also the preferred explanation among many of the researchers investigating the relationship between empathy and political views (Loewen et al., 2019; Wagaman \& Segal, 2014; Westman \& Lewandowski, 1991). Leaving these important points aside, however, an even more compelling case for thinking that empathy levels causally influence political beliefs comes from studies conducted by Sidanius and his associates.

Sidanius et al. (2013) set out to explore the relationship that holds between general empathy and Social Dominance Orientation (SDO), which predicts political conservatism. In addition to exploring the relationship between empathy and SDO, Sidanius and his colleagues also investigated the connection between empathy and three dimensions of political ideology including conservatism. ${ }^{\mathrm{xxi}}$ In support of the view that the causal arrow runs from empathy to political ideology and not vice versa, Sidanius et al. (2013) found that while empathy had a significant effect on all three political ideologies that they tested for-including conservatism-none of the political ideologies had a significant effect on empathy. It is important to note that in both of their studies, empathy and SDO were found to 
have a causal influence on each other whereby a higher measure of the one was associated with a lower measure of the other. This suggests that SDO-which Sidanius et al. consider to fall outside the category of political ideology and which evidence suggests may be correctly considered to be a personality trait like empathy—may itself play a causal role in decreasing empathy while increasing conservative political views. That is to say that the research of Sidanius and his associates lends credence to the view that the correlation between empathy and liberalism is mediated by a third factor; namely, SDO. This acknowledgement, however, does not weaken the case that their research makes for the idea that empathy causally influences political beliefs and behaviors. As I already mentioned, they provide evidence that empathy directly impacts political ideology while the opposite direction of cause does not hold. Secondly, since their studies indicate that empathy causally impacts SDO, and SDO itself seems to causally influence political attitudes, it is reasonable to conclude that empathy can also have an indirect causal impact on political views via its influence on SDO. All told, the work of Sidanius and his associates lends support for the claim that empathy causally impacts people's political views.

\section{Empathy and Political Polarization in the U.S.}

If, as the evidence suggests, empathy plays some causal role in bringing about the general ideological differences between liberals and conservatives, then it appears that differences in individual levels of empathy can go at least some of the way towards explaining the substantial partisan divide that is a defining feature of the current U.S. political landscape. There is further evidence, however, that empathy (or a lack thereof) may be making a significant contribution to this divide. Ravi lyer (2010) conducted a study indicating that while a liberal's interest in politics bears a positive correlation with their general level of empathy, a conservative's interest in politics displays the opposite pattern. The implication, as Thomas Edsall (2012) points out, is that "the more interested in politics a conservative is, the lower his (or her) level of empathy. Liberals move in the opposite direction: the more interested in politics they are, the more empathetic". Iyer's (2010) research is consistent with other studies conducted on voter patterns in the U.S. For instance, the Pew Research Center (2014) observes that those with the strongest liberal and conservative attitudes are the ones most actively involved in politics. Recall also the studies conducted by Loewen et al. (2019) indicating that one's empathy levels are positively correlated with liberal views, implying that staunch liberals have the most empathy while staunch conservatives have the least. If the patterns identified by the Pew Research Center and Loewen et al. hold true for the general U.S. population, therefore, we should expect exactly what lyer found-namely, that the empathy divide among liberals and conservatives grows in relation to group members' interest in politics. And this finding could help explain the growing political divide among the U.S. electorate insofar as it appears that those with the most empathy (i.e., the far left) and those with the least empathy (i.e., the far right) have increasingly comprised a greater proportion of the U.S. voting population (Pew Research Center, 2014). At the very least, the potential connection between empathy and contemporary voting patterns in the U.S.-including growing polarization-merits further investigation. Future studies could explore to what extent, if any, differences in empathy levels among the electorate are driving voting patterns by controlling for other variables that may also be contributing to polarization (e.g., increasingly partisan mass media, etc.). Another research project could investigate whether the empathy gap among liberals and conservatives has widened in recent years and, if so, the extent to which this phenomenon has influenced voting behavior. Furthermore, if it should turn out that differences in empathy can help explain increasing political polarization in the U.S., there would still be important questions to ask with regard to this phenomenon. Perhaps most importantly, we still would not know why empathy is a motivating factor for political engagement such that those U.S. citizens exhibiting average levels of empathy are less politically active than citizens that measure either high or low in empathy. This is another question that future research could address. 
Before concluding, I will briefly return to Bloom's claim that the similarity among liberals and libertarians on a number of policies_-including the legalization of recreational drugs and gay marriage-indicates that empathy is not a strong predictor of political attitudes. As he puts it, "if such policies are grounded in empathy, it is mysterious why the least empathetic people on earth [libertarians] would also endorse them" (Bloom, 2016, p. 122). Dispelling this mystery is not so difficult once we realize that there are likely to be different explanations for why liberals and libertarians support these positions. For the liberal, the explanation is likely to be that empathy is doing a significant amount of the motivational work. The research linking empathy to both liberal party identification and liberal policy preference provides support for this. For libertarians, however, it is not the pull of empathy, but rather adherence to a particular moral perspective-namely, one in which the concept of individual liberty figures centrally-that appears to be motivating the support of their preferred policies. Acknowledging this fact should not be taken to cast doubt on the claim that empathy positively correlates with (and probably tends to produce) liberal political views. The claim is not that empathy is the only predictor of policy preferences, but rather that empathy correlates with, and likely influences, such preferences.

\section{Conclusion}

In this essay I have argued that empirical research on the relationship between empathy and political attitudes indicates that empathy is positively correlated with both liberal ideology in general and specific liberal policy preferences. And while this correlation does not necessarily imply that empathy plays some causal role in determining a person's political views, a causal explanation along these lines seems the best way to account for the correlation. At the very least, the evidence places the burden of proof on those like Bloom who claim that general levels of empathy do not correlate with liberal political views. Finally, I discussed how the difference in empathy among liberals and conservatives appears to correspond in degree to their engagement in politics. Given studies suggesting a large discrepancy in empathy among the most politically active liberals and conservatives, this discrepancy could help explain the extensive political polarization that characterizes contemporary U.S. politics. Future research will play a pivotal role in illuminating these issues. My hope is that the analysis provided in this essay can help us better understand how personality traits can be used to predict voter attitudes.

\section{Notes}

i) According to the consensus view, therefore, high levels of empathy should be associated with a preference for the kinds of policies generally favored by liberals. I discuss what some of these policies are below.

ii) I have addressed these issues elsewhere (Morris, 2019).

iii) It should be mentioned here that while the research of Feldman and Johnston (2014) indicates a low to moderate correlation between economic and social political ideology, it also shows that there can be significant divergence along these two dimensions among self-identified liberals and conservatives. Even so, adhering to the unidimensional liberal-conservative dichotomy that is typically employed in research on U.S. voting patterns seems appropriate given the present aim of understanding how empathy has contributed to the extreme political polarization we currently find in the U.S. Among the reasons for this is that party identification is very good at tracking voting behavior, which is at the heart of this polarization. As even Feldman and Johnston (2014) acknowledge - and Jost et al. (2009) have demonstrated—self-identification as either a liberal or conservative is a reliably good predictor of political outcomes (pp. 340, 352).

iv) See, for example, my discussion of Waytz et al. (2016) below. 
v) These policies include increased government spending on healthcare, efforts to decrease wealth inequality, efforts to help disadvantaged or at-risk populations (e.g., Blacks, children and the elderly), and increased government action in general.

vi) Summing up their results, Wagaman and Segal (2014) state that "The dependent variable, attitudes toward government intervention, was correlated with the independent variable, interpersonal empathy $\left(r^{2}=.317, p<.01\right) \ldots$ interpersonal empathy alone accounted for $9 \%$ of the variance in attitudes toward government intervention" (p. 106). The measure of general empathy used in this study was the EAI.

vii) Hasson et al. (2018) note that this result demonstrates "a significant main effect of political ideology on empathic reactions, $F(1,892)=32.4, p<.001, d=.38)$ " (p. 1456). The measure of general empathy used in this study was the PVQ-R.

viii) More specifically, Loewen et al. (2019) found that "across the range of empathy values [from the lowest possible empathic capacity to the highest], the probability of identifying with the Conservative party decreases by approximately 9 percentage points from 25 percent to 16 percent, or more than a third of the starting value" (In prep.) In contrast, shifting from the lowest to the highest empathy scores results in a $40 \%$ increase in support for the center-left Liberal Party and almost a $50 \%$ increase in support for the left-leaning New Democratic Party. The authors found a significant effect of empathy on party preference such that an increase in empathy increases the likelihood that subjects will identify with the Liberal Party as opposed to the Conservative party $(p<.001)$.

ix) This study measured general empathy via the IRI. The correlation between low empathy and climate change denial was significant $(p<.05)$.

$x)$ The measure of general empathy used in this study was the EAl.

xi) To measure general empathy, Unnever et al. used several questions from an updated version of the IRI developed by Smith (2003) as well as two items taken from the Daily Spiritual Experience Scale (DSES) developed by Underwood and Teresi (2002). The items taken from the updated IRI are very similar to what we find in the original IRI, the EAI and the EQ-e.g., "Sometimes I don't feel very sorry for other people when they are having problems". The two items taken from the DSES were: (1) "I accept others even when they do something that I think is wrong;" and (2) "I feel a selfless caring for others."

xii) The measure of general empathy used in this study was the EQ.

xiii) There were a number of different empathy measures used in the seven different studies discussed by Waytz et al. (2016) Study 1 -in which liberals were found to report feeling more empathic concern than conservatives both in general and with regard to friends but not with regard to family-employed the IRI. Study 2 -which indicated that liberals report more love towards friends and non-family than conservatives but conservatives report feeling more love towards family — used the Love For Humanity scale developed by Campos, Keltner, and Gonzaga (2002). Study 3-which indicated that liberals have more universal compassion than conservatives-employed an earlier version of the PVQ-R. Study 4-which found that while liberals identify more with people in a global sense, conservatives identify more with community and country—used the Identification With All Humanity Scale developed by McFarland and Brown (2008). Study 5-which suggested that liberals show greater concern towards non-human entities than conservatives-employed the Anthropomorphism Questionnaire developed by Waytz, Cacioppo, and Epley (2010). For Study 6-in which liberal subjects dispersed valued goods over a wider range of targets (e.g., immediate family, closest friends, people on your continent, all animals on earth, etc.) than conservative subjects-Waytz and his colleagues identified liberal and conservative subjects and asked them to allocate 100 hypothetical "moral units" among these various target groups. For Study 7-in which there was no significant difference between liberals and conservatives with regard to the total amount of "moral units" given out to same target groups that appeared in Study 6 -Waytz et al. gave subjects an unlimited amount of "moral units" to disperse.

xiv) Intolerance was measured a number of ways in the studies drawn upon by Brandt et al. (2014) including a like-dislike scale, a willingness to deny basic constitutional rights to others, and a willingness to discriminate.

$\mathrm{xv}$ ) For those who agree with Bloom and Waytz et al. that differences in empathy among liberals and conservatives has more to do with the focus of empathy-in this case the specific targets of empathy—rather than personal levels of empathy, one might see a parallel in the work of Janoff-Bulman and Carnes (2013). Their research suggests that it is not variance in the emphasis placed on moral considerations (or "levels of morality") that drives differences among liberals and conservatives in the moral realm, but rather a divergence in terms of what the moral focus of liberals and conservatives is with regard to groups. 
Their research indicates that whereas conservative group-based morality focuses on social order (which is characterized by social stability and protecting against harms by others), liberal group-based morality focuses on social justice (which is characterized by social change and promoting the welfare of others).

xvi) For other specific examples of the kinds of prompts used in the studies that form the basis of Brandt et al.'s conclusions, see Wetherell, Brandt, and Reyna (2013).

$x v i i)$ Subjects in the $P V Q-R$ questionnaire were prompted to "Please read each description and think about how much that person is or is not like you."

xviii) While Hasson et al. (2018) found that liberals were more willing to help others in the U.S. and Germany, there was no significant difference in this measure among Israeli subjects.

xix) It is worth noting that some of the studies used by Waytz and his colleagues to support their position do, in fact, suggest a more general difference in empathy levels among liberals and conservatives. For instance, in the first two studies they discuss, liberals demonstrated more empathy than conservatives both in general and towards their friends. It was only when subjects in these studies were asked to report the empathy they felt towards family that liberals did not admit of higher empathy than conservatives (see Waytz et al., 2016, pp. 68-69).

xx) These political psychologists include Adorno, Frenkel-Brunswik, Levinson, \& Sanford, 1950; Lasswell, 1930; and Wilson, 1973.

xxi) In the first of their studies, Sidanius and his colleagues used the IRI to measure general empathy. For the second study they measured general empathy via three items from the Compassion Facet of Agreeableness developed by DeYoung, Quilty, and Peterson (2007). The items asked subjects the degree to which they "Sympathize with others' feelings," "Am not interested in other people's problems," and "Feel others' emotions."

\section{Funding}

The author has no funding to report.

\section{Competing Interests}

The author has declared that no competing interests exist.

\section{Acknowledgments}

I would like to thank Rob Lovering, Lacey Sischo, and two anonymous referees for providing valuable feedback on this commentary.

\section{References}

Adorno, T., Frenkel-Brunswik, E., Levinson, D., \& Sanford, R. (1950). The authoritarian personality. New York, NY, USA: W.W. Norton.

Alford, J., Funk, C. L., \& Hibbing, J. R. (2005). Are political orientations genetically transmitted? American Political Science Review, 99, 153-167. https://doi.org/10.1017/S0003055405051579

Baron-Cohen, S., \& Wheelwright, S. (2004). The empathy quotient: An investigation of adults with Asperger syndrome or high functioning autism, and normal sex differences. Journal of Autism and Developmental Disorders, 34, $163-175$. https://doi.org/10.1023/B:JADD.0000022607.19833.00

Baron-Cohen, S., Wheelwright, S., \& Jolliffe, T. (1997). Is there a "language of the eyes"? Evidence from normal adults and adults with autism or Asperger syndrome. Visual Cognition, 4, 311-331. https://doi.org/10.1080/713756761 
Batson, C. D. (2009). These things called empathy: Eight related but distinct phenomena. In J. Decety \& W. Ickes (Eds.), The social neuroscience of empathy (pp. 3-15). Cambridge, MA, USA: MIT Press.

Bloom, P. (2016). Against empathy: The case for rational compassion. New York, NY, USA: Ecco.

Brandt, M., Reyna, C., Chambers, J., Crawford, J., \& Wetherell, G. (2014). The ideological-conflict hypothesis: Intolerance among both liberals and conservatives. Current Directions in Psychological Science, 23(1), 27-34. https://doi.org/10.1177/0963721413510932

Campos, B., Keltner, D., \& Gonzaga, G. (2002). Different kinds of love: How love experiences differ across relationships. Poster presented at the annual meeting of the Western Psychological Association, Irvine, CA, USA.

Carson, J., Crespin, M., Finocchiaro, C., \& Rohde, D. (2007). Redistricting and party polarization in the U.S. House of Representatives. American Politics Research, 35(6), 878-904. https://doi.org/10.1177/1532673X07304263

Davis, M. H. (1980). A multidimensional approach to individual differences in empathy. Catalog of Selected Documents in Psychology, 10, 85.

Decety, J., \& Cowell, J. (2014). Friends or foes: Is empathy necessary for moral behavior? Perspectives on Psychological Science, 9(5), 525-537. https://doi.org/10.1177/1745691614545130

Decety, J., \& Cowell, J. (2015). Empathy, justice, and moral behavior. AJOB Neuroscience, 6(3), 3-14. https://doi.org/10.1080/21507740.2015.1047055

Deutsch, F., \& Madle, R. (1975). Empathy: Historic and current conceptualizations, measurements, and a cognitive theoretical approach. Human Development, 18, 267-287. https://doi.org/10.1159/000271488

DeYoung, C. G., Quilty, L. C., \& Peterson, J. B. (2007). Between facets and domains: 10 aspects of the Big Five. Journal of Personality and Social Psychology, 93, 880-896. https://doi.org/10.1037/0022-3514.93.5.880

Dillard, J., \& Hunter, J. (1989). On the use and interpretation of the Emotional Empathy Scale, the Self-Consciousness Scales, and the Self-Monitoring Scale. Communication Research, 16, 104-129. https://doi.org/10.1177/009365089016001005

Edsall, T. (2012, April 29). Finding the limits of empathy. New York Times. Retrieved from https://campaignstops.blogs.nytimes.com/2012/04/29/finding-the-limits-of-empathy/

Feldman, S., \& Johnston, C. (2014). Understanding the determinants of political ideology: Implications of structural complexity. Political Psychology, 35(3), 337-358. https://doi.org/10.1111/pops.12055

Gazzola, V., Aziz-Zadeh, L., \& Keysers, C. (2006). Empathy and the somatotopic auditory mirror system in humans. Current Biology, 16, 1824-1829. https://doi.org/10.1016/j.cub.2006.07.072

Goetz, J. L., Keltner, D., \& Simon-Thomas, E. (2010). Compassion: An evolutionary analysis and empirical review. Psychological Bulletin, 136(3), 351-374. https://doi.org/10.1037/a0018807

Green, E. (2014, September 18). Do liberals really care more about empathy than conservatives? The Atlantic. Retrieved from https://www.theatlantic.com/politics/archive/2014/09/liberals-care-more-about-empathy-than-conservatives/380404/

Hare, C., \& Poole, K. (2014). The polarization of contemporary American politics. Polity, 46(3), 411-429.

https://doi.org/10.1057/pol.2014.10

Hasson, Y., Tamir, M., Brahms, K., Cohrs, J., \& Halperin, E. (2018). Are liberals and conservatives equally motivated to feel empathy toward others? Personality and Social Psychology Bulletin, 44(10), 1449-1459.

https://doi.org/10.1177/0146167218769867 
Hoffman, M. L. (2001). Empathy and moral development: Implications for caring and justice. Cambridge, United Kingdom: Cambridge University Press.

lyengar, S., Konitzer, T., \& Tedin, K. (2018). The home as a political fortress: Family agreement in an era of polarization. The Journal of Politics, 80(4), 1326-1338. https://doi.org/10.1086/698929

Iyer, R. (2010, February 12). A difference between democrats and republicans - The effects of empathy on political interest. YourMorals Blog. Retrieved from http://www.yourmorals.org/blog/2010/02/a-difference-between-democrats-and-republicans-\%E2\%80\%93-the-effects-of-empathy -on-political-interest/

Janoff-Bulman, R., \& Carnes, N. (2013). Surveying the moral landscape: Moral motives and group-based moralities. Personality and Social Psychology Review, 17(3), 219-236. https://doi.org/10.1177/1088868313480274

Jost, J. T., Federico, C. M., \& Napier, J. L. (2009). Political ideology: Its structure, functions, and elective affinities. Annual Review of Psychology, 60, 307-337. https://doi.org/10.1146/annurev.psych.60.110707.163600

Jylhä, K. M., \& Akrami, N. (2015). Social dominance orientation and climate change denial: The role of dominance and system justification. Personality and Individual Differences, 86, 108-111. https://doi.org/10.1016/j.paid.2015.05.041

Lamm, C., Batson, C. D., \& Decety, J. (2007). The neural substrate of human empathy: Effects of perspective-taking and cognitive appraisal. Journal of Cognitive Neuroscience, 19, 42-58. https://doi.org/10.1162/jocn.2007.19.1.42

La Raja, R., \& Schaffner, B. (2015). Campaign finance and political polarization: When purists prevail. Ann Arbor, MI, USA: University of Michigan Press.

Lasswell, H. (1930). Psychopathology and politics. Chicago, IL, USA: University of Chicago Press.

Levendusky, M. (2013). How partisan media polarize America. Chicago, IL, USA: University of Chicago Press.

Lietz, C. A., Gerdes, K. E., Fei, S., Geiger, J. M., Wagaman, M. A., \& Segal, E. A. (2011). The Empathy Assessment Index (EAI): A confirmatory factor analysis of a multidimensional model of empathy. Journal of the Society for Social Work and Research, 2(2), 104-124. https://doi.org/10.5243/jsswr.2011.6

Loewen, P., Cochrane, C., \& Arsenault, G. (2019). Empathy and political preferences. Retrieved from https://www.princeton.edu/csdp/events/Loewen03162017/Empathy-and-Political-Preferences-Jan-2017.pdf

McFarland, S., \& Brown, D. (2008). Who believes that identification with all humans is ethical? Psicología Política, 36, 37-49.

Morris, S. (2019). Empathy on trial: A response to its critics. Philosophical Psychology, 32(4), 508-531. https://doi.org/10.1080/09515089.2019.1587911

Newman, B., Hartman, T., Lown, P., \& Feldman, S. (2015). Easing the heavy hand: Humanitarian concern, empathy, and opinion on immigration. British Journal of Political Science, 45(3), 583-607. https://doi.org/10.1017/S0007123413000410

Pew Research Center. (2014, June 12). Political polarization in the American public. Retrieved from http://www.people-press.org/2014/06/12/political-polarization-in-the-american-public/

Preckel, K., Kanske, P., \& Singer, T. (2018). On the interaction of social affect and cognition: Empathy, compassion and theory of mind. Current Opinion in Behavioral Sciences, 19, 1-6. https://doi.org/10.1016/j.cobeha.2017.07.010

Prinz, J. (2011). Is empathy necessary for morality? In A. Coplan \& P. Goldie (Eds.), Empathy: Philosophical and psychological perspectives (pp. 211-229). London, United Kingdom: Oxford University Press. 
Schwartz, S. (1992). Universals in the content and structure of values: Theoretical advances and empirical tests in 20 countries. In M. Zanna (Ed.), Advances in experimental social psychology (Vol. 25, pp. 1-65). San Diego, CA, USA: Academic Press.

Schwartz, S., Melech, G., Lehrnami, A., Burgess, S., Harris, M., \& Owens, V. (2001). Extending the cross-cultural validity of the theory of basic human values with a different method of measurement. Journal of Cross-Cultural Psychology, 32 , 519-542. https://doi.org/10.1177/0022022101032005001

Sidanius, J., Kteily, N., Sheehy-Skeffington, J., Ho, A., Sibley, C., \& Duriez, B. (2013). You're inferior and not worth our concern: The interface between empathy and social dominance orientation. Journal of Personality, 81(3), 313-323. https://doi.org/10.1111/jopy.12008

Smith, T. W. (2003). Altruism in contemporary America: A report from the National Altruism Study (General Social Survey Topical Report No. 34). Chicago, IL, USA: National Opinion Research Center.

Stueber, K. (2013). Measuring empathy. Stanford Encyclopedia of Philosophy. Retrieved from https://plato.stanford.edu/entries/empathy/measuring.html

Theriault, S. (2008). Party polarization in congress. Cambridge, United Kingdom: Cambridge University Press.

Tuschman, A. (2013). Our political nature: The evolutionary origins of what divides us. New York, NY, USA: Prometheus Books.

Underwood, L. G., \& Teresi, J. A. (2002). The Daily Spiritual Experience Scale: Development, theoretical description, reliability, exploratory factor analysis, and preliminary construct validity using health-related data. Annals of Behavioral Medicine, 24(1), 22-33. https://doi.org/10.1207/S15324796ABM2401_04

Unnever, J., Cullen, F., \& Fisher, B. (2005). Empathy and public support for capital punishment. Journal of Criminal Justice, 28(1), 1-34.

Voorheis, J., McCarty, N., \& Shor, B. (2015). Unequal incomes, ideology and gridlock: How rising inequality increases political polarization (Working paper). https://doi.org/10.2139/ssrn.2649215

Wagaman, M., \& Segal, E. (2014). The relationship between empathy and attitudes toward government intervention. Journal of Sociology and Social Welfare, 41(6), 91-112.

Waytz, A., Cacioppo, J., \& Epley, N. (2010). Who sees human? The stability and importance of individual differences in anthropomorphism. Perspectives on Psychological Science, 5(3), 219-232. https://doi.org/10.1177/1745691610369336

Waytz, A., lyer, R., Young, L., \& Graham, J. (2016). Ideological differences in the expanse of empathy. In P. Valdesolo \& J. Graham (Eds.), Social psychology of political polarization (pp. 61-78). New York, NY, USA: Routledge.

Weisz, E., \& Zaki, J. (2018). Motivated empathy: A social neuroscience perspective. Current Opinion in Psychology, 24, 67-71. https://doi.org/10.1016/j.copsyc.2018.05.005

Westman, A. S., \& Lewandowski, L. M. (1991). How empathy, egocentrism, Kohlberg's moral development, and Erikson's psychosocial development are related to attitudes toward war. Psychological Reports, 69, 1123-1127.

Wetherell, G., Brandt, A., \& Reyna, C. (2013). Discrimination across the ideological divide: The role of value violations and abstract values in discrimination by liberals and conservatives. Social Psychological \& Personality Science, 4(6), 658-667. https://doi.org/10.1177/1948550613476096

Wilson, G. (1973). The psychology of conservatism. San Diego, CA, USA: Academic Press. 